\title{
Functional Magnetic Resonance Imaging of Proactive Interference during Spoken Cued Recall
}

\author{
R. N. A. Henson, ${ }^{*} \dagger^{, 1}$ T. Shallice, $†$ O. J osephs,* and R. J . Dolan*'‡ \\ *Institute of Neurology, † Institute of Cognitive Neuroscience, and ¥Royal Free Hospital, University College London, \\ London WC1N 3BG, United Kingdom
}

Received J anuary 14, 2002

Though lesions to frontal cortex can increase susceptibility to interference from previously established but irrelevant memories ("proactive interference"), the specific regions underlying this problem are difficult to determine because the lesions are typically large and heterogeneous. We used event-related functional magnetic resonance imaging to investigate proactive interference in healthy volunteers performing an "AB-AC" pairedassociate cued-recall paradigm. At Study, participants intentionally encoded semantically related visual word pairs, which were changed three times (high interference), repeated three times (low interference), or presented only once. At Test, participants were presented with the first word of each pair and attempted to recall its most recent associate from the Study phase. To overcome the problem of image artifacts caused by speechrelated head motion, we cued speech during a gap between image acquisitions. Regions in left inferior frontal cortex and bilateral frontopolar cortex showed interference effects during both Study and Test. The pattern of responses in these regions differed, however. Left inferior frontal regions showed mainly reduced responses associated with low interference, whereas frontopolar regions showed mainly increased responses associated with high interference. When incorrect as well as correct trials were analyzed at Test, additional activation associated with high interference was observed in right dorsolateral prefrontal cortex. These data suggest that distinct regions within prefrontal cortex subserve different functions in the presence of proactive interference during cued recall. 2002 Elsevier Science (USA)

Key Words: proactive interference; event-related fMRI; overt speech; cued recall; inferior frontal; frontopolar; prefrontal cortex.

\section{INTRODUCTION}

Numerous imaging studies have reported activation of prefrontal cortex during long-term memory tasks

${ }^{1}$ To whom correspondence should be addressed. E-mail: r.henson@ud.ac.uk. (see Fletcher and Henson, 2001, for a recent review). While lesions to frontal cortex do not cause the classic amnesic syndrome associated with medial temporal lesions (J anowsky et al., 1989), they do produce deficits in memory for the temporal context of events (e.g., Milner et al., 1991; Shimamura et al., 1990) in the strategic organization of encoding and/or retrieval (e.g., Incisa Della Rocchetta and Milner, 1993; Stuss et al., 1994) and, in extreme cases, often associated with orbitofrontal lesions, confabulation (e.g., Moscovitch and Melo, 1997; Schnider and Ptak, 1999).

A further memory problem associated with frontal lesions is an increased susceptibility to proactive interference. Proactive interference refers to the interference between a target memory and previously formed memories. In the context of paired-associate cued recall, proactive interference results when the same cue (e.g. "queen-?") is associated with multiple responses (e.g., "queen- king", "queen- bee", "queen-crown"). If the task is to recall the most recent associate, for example, patients with frontal lesions tend to perform poorly, often erroneously recalling previous associates (e.g., Shimamura et al., 1995). One explanation for this deficit is that these patients, unlike amnesics, can retrieve previous associates, but are unable to inhibit or suppress associates that are no longer relevant (Schnider and Ptak, 1999; Shimamura, 1994).

Two previous imaging studies of healthy volunteers have demonstrated prefrontal activation in association with proactive interference at "encoding" (Dolan and Fletcher, 1997; Fletcher et al., 2000). These studies used a paired-associate learning paradigm in which a pair of words was presented under instructions to remember the pairing. Because both words were presented together, in the absence of overt recall demands, these studies could not directly measure retrieval processes per se. We examined proactive interference during retrieval in a previous PET study (Henson et al., 1998) using a cued-recall task, but with only limited success. Two limitations arose because the interference manipulation was blocked, meaning that subjects may have adopted different strategies in the 


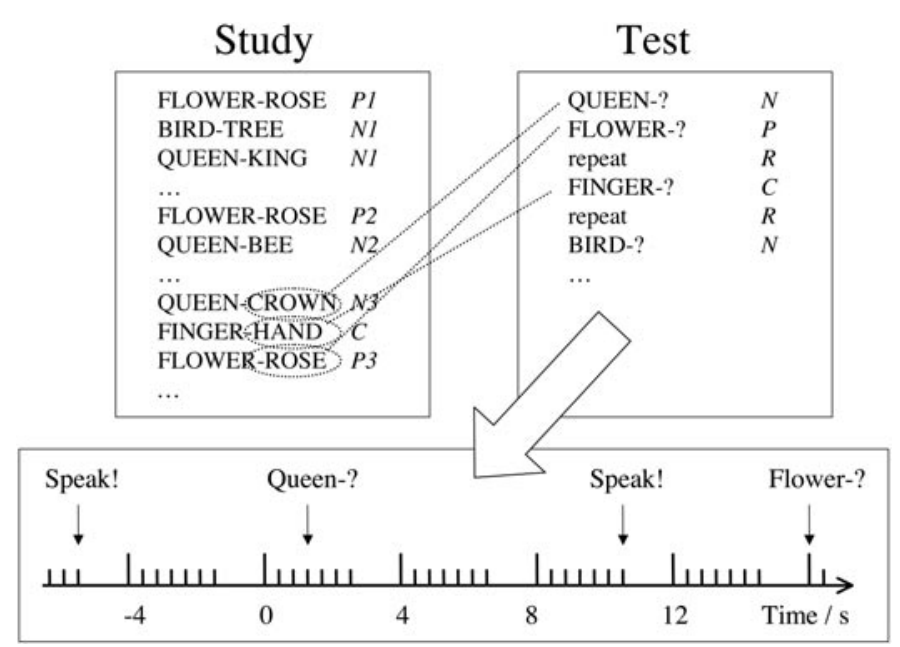

FIG. 1. Schematic of Study and Test phases. Vertical ticks on time axis at bottom illustrate example slice acquisitions; taller ticks represent the first slice per volume.

presence and absence of proactive interference and that the comparisons across conditions were confounded by differences in overall performance levels. We overcome these limitations in the present study by using event-related fMRI. This allowed us to intermix cues with different levels of proactive interference, removing potential strategic effects, and to restrict analysis to correct responses, ameliorating any difference in mean performance levels.

One problem associated with recall during fMRI, however, is the potential for movement artifacts caused by speech. This problem has tended to restrict previous fMRI studies of episodic retrieval to recognition or covert recall tasks. Recognition tasks require participants to discriminate repeated items from intermixed foils. However, correct discrimination can be based on a combination of episodic retrieval and acontextual familiarity processes (Mandler, 1980). Covert recall tasks rely on participants indicating whether they can recall an item, either online (e.g., with a key press), but with no objective measure of whether they are correct, or after scanning, but with no guarantee that the same item was in fact remembered previously in the scanner. We therefore addressed the problem of overt speech with a novel scanning procedure in which participants were cued to speak during the gap be tween scans (see Materials and Methods).

We used a version of the $A B-A C$ paired-associate paradigm to investigate proactive interference during both a Study phase and a Test phase (see Fig. 1). In the Study phase, participants intentionally encoded semantically related, cue-associate word pairs, much like the previous studies by Dolan and Fletcher (1997) and Fletcher et al. (2000). In the high or "negative" (N) interference condition, cues were presented three times, each time with a different associate (i.e., an
$A B-A C-A D$ condition). In the low or "positive" (P) interference condition, cues were presented three times with the same associate (i.e., an $A B-A B-A B$ condition). In the control $(C)$ condition, cues were presented only once with an associate (i.e., an $A B$ condition). In the Test phase, participants were presented with a cue word and attempted to recall its most recently paired associate (i.e., the "target" was the associate from the last pairing episode in the Study phase). A further nonmemory control condition was also included at Test (the R condition), in which participants saw the word "repeat" and simply said aloud "repeat" when prompted to speak. All conditions were randomly intermixed.

In general terms, greatest proactive interference, and hence greatest prefrontal activity, was expected in the $\mathrm{N}$ condition and least in the $\mathrm{P}$ condition. More specifically, differences between the $\mathrm{N}$ and the $\mathrm{C}$ conditions were expected to reflect proactive interference from the multiple different associations that had been established in the $\mathrm{N}$ condition, whereas differences between the $P$ and the $C$ conditions were expected to reflect reduced interference from other intra- and extralist items following the repeated strengthening of a single association in the $P$ condition. Comparisons of all three conditions against the $\mathrm{R}$ condition at Test also allowed identification of regions involved in general memory retrieval and of regions involved in maintaining a response during the delay between the cue and the speech events.

\section{MATERIALS AND METHODS}

\section{Participants}

Sixteen right-handed volunteers gave informed and written consent to participate in the experiment. The data from 4 participants were not analyzed: 3 because their memory performance did not reach criterion (see below) and 1 because of technical problems. The 12 subjects analyzed included 6 men and were aged 22-30 (median 27). All volunteers reported themselves to be in good health with no history of neurological illness.

\section{Materials and Procedure}

The three most frequent associates of 45 common nouns ("cues") were generated from the Edinburgh Associative Thesaurus (http://www.itd.clrc.ac.uk/ Activity/Psych+267; Kiss et al., 1973). For each subject, three groups of 15 such word-associate sets were randomly assigned to each condition: the $\mathrm{P}, \mathrm{C}$, and $\mathrm{N}$ interference conditions (see bel ow). Five sets from each of these three conditions were then randomly assigned to three Study-Test sessions.

During the Study phase of each session, a cue and its associate were displayed simultaneously for $1 \mathrm{~s}$, with 
an average stimulus onset asynchrony (SOA) of $4 \mathrm{~s}$ (jittered randomly between 3.5 and $4.5 \mathrm{~s}$ ) and with a fixation cross present during the interstimulus interval. Participants pressed a key with their right index finger to indicate that they had seen the pair of words and discovered a semantic link between them. Participants were told that some of the cue words would be repeated but with different associates, whereas others would be repeated with the same associate. They were also told that, during a subsequent memory test, the cue would be presented and they would have to recall its most recent (last) associate.

For the $\mathrm{P}$ and $\mathrm{N}$ conditions, each cue was presented three times in a study list; in the $C$ condition, each cue was presented only once. In the $P$ condition, it was paired with the same (randomly chosen) associate each time. In the $\mathrm{N}$ condition, it was paired with a different associate each time. The first and second presentations of each pair in the $\mathrm{P}$ and $\mathrm{N}$ conditions (P1, P2, N1, and N2) were randomized in order. The third presentations of each pair (P3 and N3) were randomly intermixed with the single presentations of the cue and associate of the $C$ condition (thus equating the average time between presentation and recall of the most recent associates in each condition, see Fig. 1). There were thus 35 presentations of word pairs in total. These pairs were presented on a mirror $30 \mathrm{~cm}$ above the participant, subtending a visual angle of approximately $4^{\circ}$.

During the Test phase, a cue word was displayed for $1 \mathrm{~s}$, and participants were told to retrieve the most recent associate of that cue from the Study phase. However, they were not to speak their response immediately; instead they were asked to keep it in mind for between 8 and 12 s until they saw a visual "speak!" prompt (see Fig. 1 and below), at which point they articulated the response. If they could not remember any associates, they were told simply to say "pass." Cues corresponding to the three different conditions were randomly intermixed, together with a fourth condition-the Repeat $(R)$ condition-in which the cue was the word "repeat" (presented in lowercase to distinguish it from the other cues presented in uppercase). With this cue, participants were instructed to simply respond with the same word ("repeat") when they saw the speak prompt. This R condition controlled for lowlevel visual input and spoken output, but had no episodic memory retrieval requirements. The time between the speak prompt and the next cue was jittered randomly between 4 and $8 \mathrm{~s}$ in 0.5-s intervals (such that the SOA between successive speech events was fixed at $16 \mathrm{~s}$, while the SOA between cues varied between 12 and 20 s). Participants were given examples of both Study and Test phases during a brief practice session.

\section{Speech in the Scanner}

Overt speech during fMRI image acquisition can be problematic, since it can introduce considerable movement artifact. Though some researchers have shown it possible to obtain differential activations between speech conditions (Barch et al., 1999; Palmer et al., 2001), precautions to minimize effects of speech-related movement will further improve sensitivity. One method that capitalizes on the protracted nature of the blood oxygenation level-dependent (BOLD) response is to use event-related fMRI and discard (or covary out) scans during which speech occurs (Birn et al., 1998). Assuming speech occurs shortly $(<3-4 \mathrm{~s})$ after the event of interest, the remaining scans acquired after the speech will still contain measurable BOLD signal.

A problem with this approach is that speech-related movement during multislice EPI can cause misalignment of slice selection relative to the brain, potentially disturbing the nuclear spin equilibrium. For example, if the movement exceeds the interslice gap during a sequential slice acquisition (as used in the present study for reasons given below), the same region of tissue can be excited more than once within a scan, while other regions of tissue are not excited. This can produce differential spin history effects, which decay according to the T1 relaxation time. Thus even if scans containing speech are discarded, movement-related effects can still influence subsequent scans. Furthermore, the slice misalignment caused by within-scan movement can produce image deformations that are not correctable using conventional rigid-body image realignment techniques (Friston et al., 1995a; see Data Analysis below).

Our solution to this problem was to not acquire echoplanar imaging (EPI) data during the speech event, eliminating the problem of differential T1 effects and image deformation owing to speech-related movement and avoiding the need to discard data. Subjects had ample time to prepare their spoken response, and the cue to speak was timed to coincide with the 1.2-s gap between scans (see Scanning Parameters below). Pilot studies showed that this gap was sufficient to articulate the one/two syllable responses (which typically lasted 400-500 ms), as confirmed by online monitoring of the recorded speech (see below). The absence of scanner noise during speech also improved its intelligibility, which in turn allowed participants to speak quietly and hence minimize their head movement.

Speech was recorded by a microphone via an airtube attached to the headcoil and positioned as close to the mouth as possible. The speech signal was digitized and displayed together with the scanner slice-selection pulses on a PC for online monitoring. Subjects were able to whisper and still be heard and were instructed to keep their head as still as possible throughout the scanning sessions, particularly when speaking. De- 
spite these precautions, pilot work showed some small, residual lower frequency movement, in which the head position varied gradually after the speech event. The jittered phase relationship between the speech and the cue events (see above) reduced the correlation between this residual movement effect and the effects of interest, allowing the former to be at least partially accommodated by the inclusion of the scan-to-scan realignment parameters in the statistical analysis, which covaried out linear residual movement effects.

\section{Scanning Parameters}

A 2-T Vision system (Siemens, Erlangen, Germany) was used to acquire 30 T2*-weighted transverse EP images $\left(64 \times 643 \times 3-\mathrm{mm}^{2}\right.$ pixels, TE $\left.=40 \mathrm{~ms}\right)$ with BOLD contrast. EPIs comprised 2-mm-thick axial slices taken every $3.5 \mathrm{~mm}$, acquired sequentially in a descending direction. Though an interleaved acquisition of slices would reduce movement-related multipleexcitation effects (see above), sequential acquisition is preferable when using thin slices in order to minimize the temporal realignment errors that arise owing to the inevitable across-scan movement (see http://www. fil.ion.ud.ac.uk/spm/course/manual/man.htm).

The three Study sessions comprised 53 volumes collected continuously with a repetition time (TR) of $3 \mathrm{~s}$ (acquisition time, TA $=2.8 \mathrm{~s}$ ). Test sessions comprised 88 volumes collected with a TR of $4 \mathrm{~s}$ but TA of $2.8 \mathrm{~s}$ (thus incorporating a 1.2-s gap between acquisitions for the speech event). These gaps occurred between every scan to ensure a "steady state" was reached in which nuclear spin histories were in equilibrium. The first five volumes of each session were discarded to allow for T 1 equilibration effects. The ratio of SOAs to TR ensured an effective sampling rate of the cue-related impulse response over trials of $2 \mathrm{~Hz}$.

\section{Data Analysis}

Only data from the 12 participants who recalled over $60 \%$ of associates in every condition (i.e., 9 or more of the 15 possible correct responses across the three sessions) were analyzed. Analysis was performed with statistical parametric mapping (SPM99; Wellcome Department of Cognitive N eurology, London, UK; Friston et al., 1995b) implemented in Matlab5 (The Mathworks, Inc. U.S.A.). All volumes were realigned spatially to the first volume, and the time series for voxels within each slice realigned temporally to acquisition of the middle slice. Resulting volumes were normalized to a standard EPI template based on the MNI reference brain in Talairach space (Ashburner and Friston, 1999) and resampled to $3 \times 3 \times 3-\mathrm{mm}^{3}$ voxels. No subject moved more than $\pm 2 \mathrm{~mm}$ in any direction across all sessions. The normalized images were smoothed with an isotropic 8-mm FWHM Gaussian kernel. The time series in each voxel were high-pass filtered to $1 / 120 \mathrm{~Hz}$ to remove low-frequency noise and scaled to a grand mean of 100 over voxels and scans within each session.

Statistical analysis was performed in two stages in a mixed-effects model. For analysis of the Study sessions, seven neural components were defined (P1, $P 2$, P3, C, N1, N2, N3) and treated as instantaneous events (i.e., neural activity was modeled by a delta function at stimulus onset). For analysis of the Test sessions, eight neural components were defined: (1) correct responses to $\mathrm{P}$ cues, (2) correct responses to C cues, (3) correct responses to $\mathrm{N}$ cues, (4) correct responses to R cues, (5) incorrect responses to $\mathrm{P}, \mathrm{C}, \mathrm{N}$, or R cues, (6) the delay period after $\mathrm{P}, \mathrm{C}$, and $\mathrm{N}$ cues, (7) the delay period after R cues, and (8) the speech event (for all conditions). All components except the delay components were treated as events; the delay components were treated as short epochs between the cue and the speak prompt (i.e., neural activity was modeled by a boxcar function). Thus each Test trial was modeled with three components, one for the cue event, one for the delay period, and one for the speech event.

The BOLD response in each condition was modeled by convolving these neural functions with a canonical hemodynamic response function (HRF) (Friston et al., 1998). This convolution was performed in a high-resolution time space and downsampled at the midpoint of each scan to form covariates in a general linear model. Though the resulting covariates for the different trial components were correlated, their simultaneous inclusion in the model allows identification of the unique (orthogonal) component of variability attributable to each. Furthermore, by modeling the delay-related response as common to $\mathrm{P}, \mathrm{C}$, and $\mathrm{N}$ conditions, this correlation did not reduce the power to detect differences between cue-related responses to $\mathrm{P}, \mathrm{C}$, and $\mathrm{N}$ cues. Also included for each session were six covariates to capture residual movement-related artifacts (the three rigid-body translations and three rotations determined from the realignment stage) and a single covariate representing the mean (constant) over scans. Parameters for each covariate were estimated by a leastsquares fit to the data. Linear contrasts of these parameter estimates, averaged across sessions within each participant, comprised the data for the second stage of analyses (Holmes and Friston, 1998).

For both Study and Test phases, parameter estimates for the $N, C$, and $P$ conditions were entered into a one-way, repeated measures analysis of variance (ANOVA), treating subjects as a random variable. SPMS of the F statistic for the main effect of condition were created, with the degrees of freedom corrected for nonsphericity by a Greenhouse-Geisser correction at each voxel (Glaser et al., 2001). These SPM $\{F\}$ maps were thresholded for at least three contiguous voxels surviving $\mathrm{P}<0.001$, uncorrected for multiple comparisons over voxels. These maps were then used as masks, voxels within which were examined in planned, 
one-tailed t tests for $\mathrm{N}-\mathrm{C}$ and $\mathrm{C}-\mathrm{P}$ contrasts. This was performed by creating SPM $\{\mathrm{T}\}$ maps for each test and thresholding at $\mathrm{P}<0.05$, volume corrected for the voxels in the mask (Worsley et al., 1995).

Two further exploratory analyses were performed on the Test trials. The first compared the average cuerelated response in $\mathrm{P}, \mathrm{C}$, and $\mathrm{N}$ conditions against that in the nonmemory $\mathrm{R}$ condition, to detect regions showing a main effect of cued recall. The second compared the corresponding delay-related response of memory versus nonmemory conditions, to detect regions showing, for example, an effect of maintaining retrieved information in mind between the cue and the speech event.

Regions showing significant effects were localized as best as possible on the mean normalized EPI across subjects, to allow for the susceptibility and distortions in the EPI images. Stereotactic coordinates are re ported in Talairach space and correspond to the standard MNI brain (Cocosco et al., 1997). These coordinates bear a close, but not exact, match to the Talairach and Tournoux (1988) atlas, which was used to estimate the regions of Brodmann (1909).

\section{RESULTS}

\section{Behavioral Results}

The mean proportions of correct responses were 0.96 , 0.81 , and 0.72 for $\mathrm{P}, \mathrm{C}$, and $\mathrm{N}$ conditions, respectively. Pair-wise $t$ tests on arcsin-transformed proportions confirmed that memory performance was significantly better in the $P$ than in the $C$ condition, $t(12)=3.55$, $\mathrm{P}<0.001$, and significantly better in the $\mathrm{C}$ than in the $\mathrm{N}$ condition, $\mathrm{t}(12)=2.16, \mathrm{P}<0.05$. The proportions of intraset intrusions (from the set of three closest semantic associates to each cue, see Materials and Methods) were $0.01,0.07$, and 0.23 for $\mathrm{P}, \mathrm{C}$, and $\mathrm{N}$ conditions, respectively, confirming that the majority of errors in the $\mathrm{N}$ condition reflected proactive interference from other associates presented at study (the remaining errors were semantically related, extralist intrusions, particularly in the $C$ condition, together with a small number of intralist intrusions and "passes").

\section{Imaging R esults}

\section{Interference Effects at Study}

Comparisons at Study were restricted to the third presentations of $\mathrm{P}$ and $\mathrm{N}$ conditions (P3 and N3), together with the $C$ condition, to control for time effects within the Study phase. Regions showing a main effect of condition are shown in Table 1. These included several regions within left inferior frontal cortex, together with bilateral frontopolar cortex, left lateral fusiform cortex, left lateral occipital sulcus, precuneus/trans- verse parietal sulcus, and right posterior superior temporal sulcus.

Several of these regions showed significant pair-wise differences between N3 and C conditions (upper row of Fig. 2) and/or P3 and C conditions (middle row of Fig. 2). The bilateral frontopolar (regions B and C) and the precuneus (region $E$ ) regions, identified by the N3 versus $\mathrm{C}$ comparison (and $\mathrm{P} 3$ versus $\mathrm{C}$ comparison in the case of the right frontopolar and precuneus regions), showed greater responses for repeated versus initial presentations of a cue, whether the target was maintained (P2 and P3) or changed (N2 and N3), but little evidence of further increases across second and third presentations.

The left inferior frontal regions identified by the $C$ versus P3 comparison comprised two ventrolateral re gions, in ventral (region A) and anterior (not shown in Fig. 2) aspects of inferior frontal gyrus, and a region in inferior frontal sulcus (region D), extending posteriorly into precentral sulcus and probably including aspects of both ventrolateral (BA 45) and dorsolateral (BA 9/46) prefrontal cortex. These regions all showed responses that decreased with successive presentations of the same cue-target pair (i.e., from P1 to P3), but increased when the cuetarget pairing changed (from $\mathrm{N} 1$ to N2, though there was little sign of a further increase from N2 to N3). The right superior temporal region identified by the $\mathrm{P} 3$ versus $\mathrm{C}$ comparison (graphs not shown) was maximal for repeated cuetarget pairs (P3), but showed little effect of changed pairings (N2/N3).

\section{Interference Effects at Test}

Correct trials. Regions showing a main effect of interference at Test are shown in Table 2. These regions included two regions in left inferior frontal cortex, as well as regions in bilateral frontopolar cortex, anterior cingulate sulcus, bilateral head of caudate, left thalamus, midcerebellum, left precuneus/medial superior parietal gyrus, and right intraparietal sulcus.

Several of the regions showed significant differences between $\mathrm{N}$ and $\mathrm{C}$ conditions (upper row of Fig. 3) or $\mathrm{P}$ and $\mathrm{C}$ conditions (middle row of Fig. 3). The bilateral frontopolar regions (regions $B$ and $C$ ) and precuneus region (region $\mathrm{E}$ ) showed greatest responses to the $\mathrm{N}$ condition, but little difference between $C$ and $P$ conditions. A similar pattern was seen for the caudate, midcerebellum, and right intraparietal regions (graphs not shown).

The two left inferior frontal regions, most likely in lateral orbital gyrus (region F) and inferior frontal gyrus (region $A$ ), exhibited greater responses for the $C$ than for the $P$ condition, though little difference between the $\mathrm{C}$ and the $\mathrm{N}$ conditions. The left anterior thalamus region exhibited a more graded pattern of increasing responses across $\mathrm{P}, \mathrm{C}$, and $\mathrm{N}$ conditions (see 

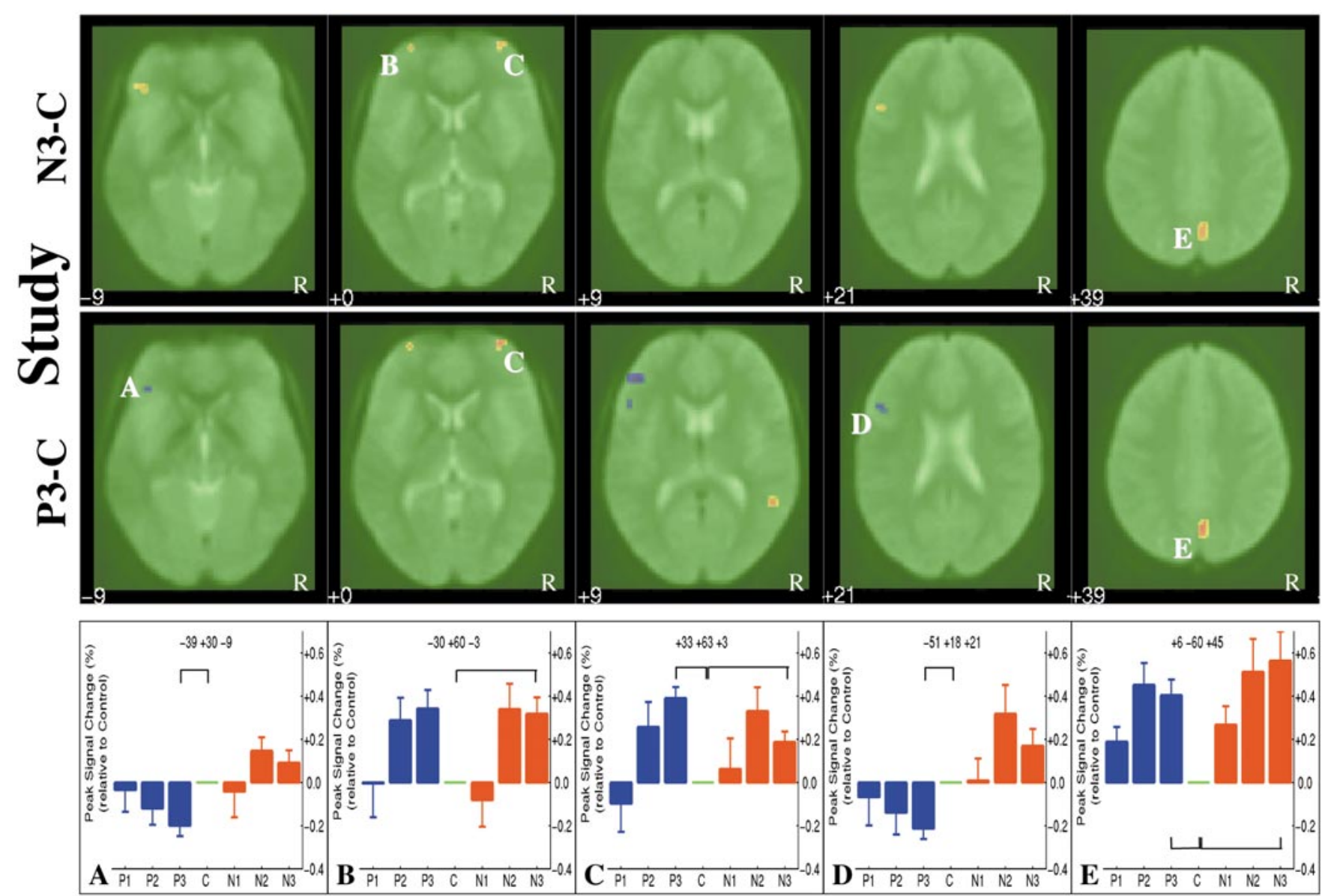

FIG. 2. Interference effects at Study. Transverse sections ( $z$ coordinate at bottom left) through the mean normalized EPI across participants. Colored regions show main effect of $P, C$, and $N$ conditions $(P<0.001$, uncorrected) and pair-wise differences $(P<0.05$, two-tailed, uncorrected) for N3 vs C (upper row of sections) and P3 vs C (second row of sections). Increases versus C are in orange; decreases in blue. Bottom row shows percentage BOLD signal change (relative to grand mean over voxels and scans) at the peak of the best-fitting canonical HRF for P1-P3 (blue) and N1-N3 (red) events relative to C events (green), from the maxima of regions A-E. Error bars show the standard errors of the differences relative to $C$ condition (the rapid presentation precluded accurate measurement of interstimulus basel ine). The horizontal brackets indicate the contrasts that identified the area.

region $\mathrm{N}$ in Fig. 5), as did the region in dorsal anterior cingulate sulcus, for which the pattern persisted into the delay period (see region $\mathrm{K}$ in Fig. 6).

Post hoc $2 \times 3$ ANOVAs with factors of region (lateral inferior frontal versus frontopolar) and interference condition ( $P, C$, and $N$ ) confirmed that the pattern of interference effects differed between lateral inferior and frontopolar cortices, regardless of whether either the orbital or the ventrolateral inferior frontal region was tested against either the left or the right frontopolar regions, interaction $\mathrm{F}>6.37, \varepsilon>0.87, \mathrm{P}<0.01$. No interactions with condition were found between the two lateral inferior regions or between the left and the right frontopolar regions.

\section{Interference Effects at Test}

All trials. Following the suggestion of a reviewer, we reanalyzed the Test data by collapsing together all trials, regardless of whether the response was correct or incorrect. The results are shown in Table 3 and Fig. 4. The pattern of interference was largely similar to that arising when correct trials alone were considered. One notable difference was the absence of frontopolar differences (though these regions were present at a lower threshold). More interesting was the emergence of a significant interference effect in anterior right inferior frontal sulcus (region J), most likely corresponding to dorsolateral prefrontal cortex. This region was more active for the $\mathrm{N}$ condition than for $\mathrm{C}$ or $\mathrm{P}$ condition (like frontopolar cortex above).

\section{Other Effects at Test}

Two further exploratory analyses compared the memory conditions ( $P, C$, and $N$ ) against the nonmemory $\mathrm{R}$ condition, in terms of both the transient response to the cue and the sustained response during 

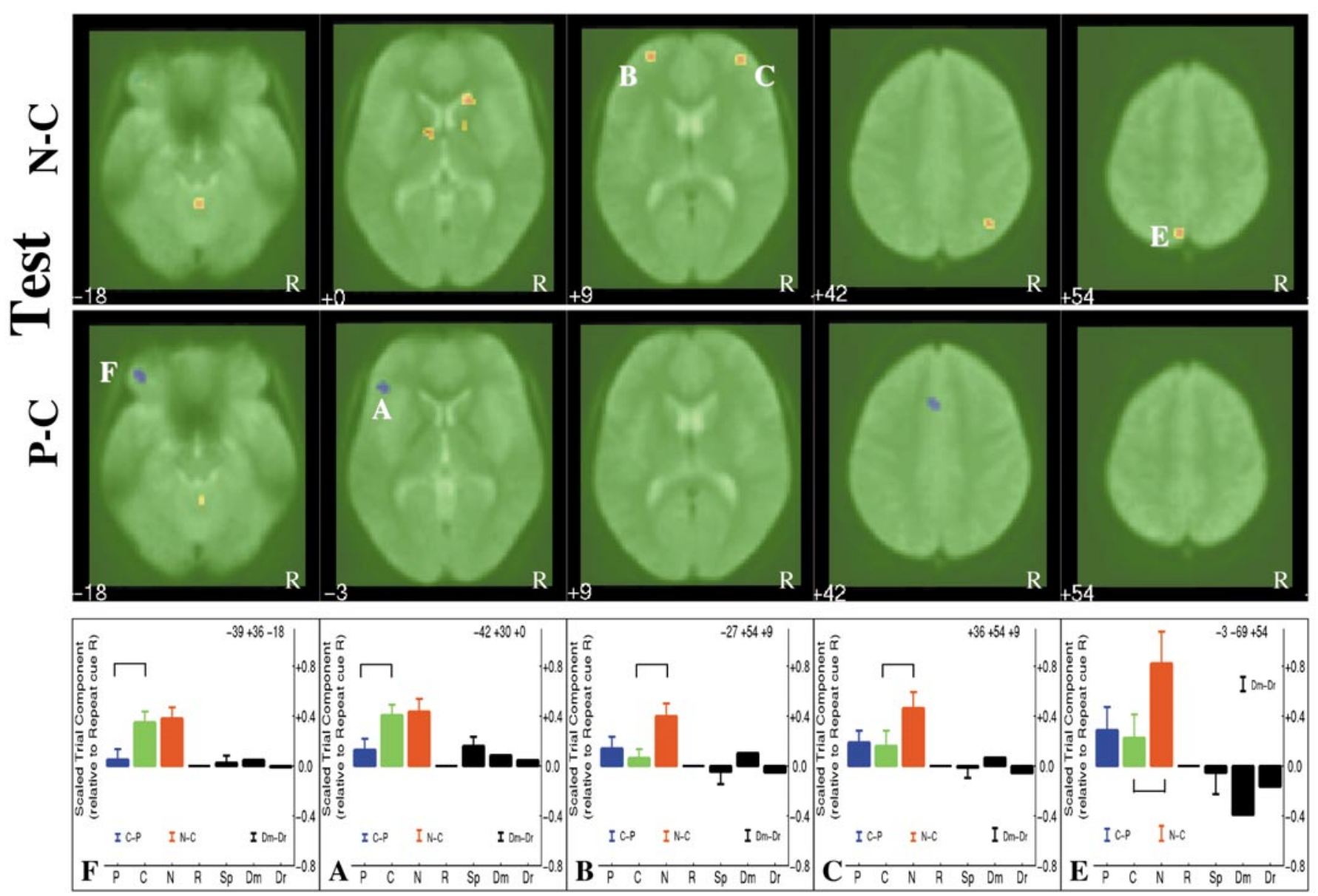

FIG. 3. Interference effects at Test, correct trials only. Col ored regions show main effect of $P, C$, and $N$ conditions (P $<0.001$, uncorrected) and pair-wise differences ( $P<0.05$, two-tailed, uncorrected) for $N$ vs $C$ (upper row of sections) and $P$ vs $C$ (second row of sections). Bottom row shows estimates of the cued-related $(\mathrm{P}, \mathrm{C}, \mathrm{N})$ ), delay-related (Dm and Dr), and speech (Sp) components of trials (see Materials and Methods), relative to the cue-related component in $\mathrm{R}$ trials, from the maxima of regions $\mathrm{A}-\mathrm{F}$. Inset are the standard errors of the $\mathrm{C}-\mathrm{P}$, $\mathrm{N}-\mathrm{C}$, and Dm-Dr contrasts. See legend to Fig. 2 for more details.

the delay between the cue and the speech prompt (see Materials and Methods).

Memory-related cue effects. Regions showing transient cue-related responses associated with recall are shown in Table 4 and Fig. 5. Regions showing greater responses to memory than repeat cues, most notably in bilateral medial temporal cortices (regions $L$ and $M$ ), bilateral thalami (e.g., region $\mathrm{N}$ ), bilateral anterior insulae (extending into ventrolateral prefrontal cortex/ frontal operculum on the left, close to region A in Fig. 3), bilateral posterior occipital cortices, bilateral precentral sulci (e.g., region $\mathrm{P}$ in premotor cortex, but also extending along the inferior frontal sulcus on the left to probably include aspects of dorsolateral prefrontal cortex, as in region S in Fig. 6), anterior cingulate sulcus, and bilateral intraparietal sulci. The medial temporal regions appeared to include anterior hippocampi, but cannot be localized unambiguously to such small structures, given the smoothed, group-averaged, and possibly deformed nature of the EPI data. Most of these regions also showed a (nonsignificant) trend for increased responses to memory cues with increasing levels of proactive interference. A region in right posterior superior temporal sulcus, however, extending into angular gyrus (region 0 ), showed a reduced response to memory versus repeat cues.

For a subset of regions, including those in bilateral insulae, left dorsolateral prefrontal, anterior cingulate, and left lateral parietal cortices, the memory-related response enhancement was maintained during the cuespeech interval, as was the memory-related response decrease in right posterior superior temporal cortex, as described below.

Memory-related delay effects. Regions showing memory-related responses during the delay between cue and speech are shown in Table 5 and Fig. 6. These regions were identified by comparing the parameter estimate for the delay period of memory trials (Dm, middle row of Fig. 6), common to $\mathrm{P}, \mathrm{C}$, and $\mathrm{N}$ conditions, against that for the repeat condition (Dr). The 
TABLE 1

Regions Showing Main Effect of Interference at Study in F Tests at P $<0.001$ Uncorrected, Together with Z Scores for Pair-wise Comparisons versus Control Condition That Survive $\mathrm{P}<0.05$ Volume Corrected for Main Effect

\begin{tabular}{|c|c|c|c|c|c|c|c|c|c|}
\hline \multirow[b]{2}{*}{ Region } & \multirow[b]{2}{*}{$\mathrm{L} / \mathrm{R}$} & \multirow[b]{2}{*}{ Size $\left(\mathrm{cm}^{3}\right)$} & \multirow[b]{2}{*}{ BA } & \multicolumn{3}{|c|}{ Coordinates } & \multicolumn{3}{|c|}{ Z } \\
\hline & & & & $x$ & $y$ & z & $\mathrm{N} 3>\mathrm{C}$ & $C>P 3$ & $\mathrm{P} 3>\mathrm{C}$ \\
\hline \multirow[t]{2}{*}{ Frontopolar } & L & 0.08 & 10 & -30 & 60 & -3 & 3.18* & & \\
\hline & $\mathrm{R}$ & 0.22 & 10 & 33 & 63 & 3 & $3.41 *$ & & $4.41 *$ \\
\hline Anterior inferior frontal & L & 0.35 & 45 & -45 & 39 & 9 & & $3.96 *$ & \\
\hline Ventral inferior frontal & $\bar{L}$ & 0.19 & 47 & -39 & 30 & -9 & & $3.20 *$ & \\
\hline \multirow{2}{*}{ Posterior inferior frontal } & L & 0.94 & $45 / 46$ & -45 & 24 & 12 & & $4.26 *$ & \\
\hline & & & $9 / 45$ & -51 & 18 & 21 & & $3.24 *$ & \\
\hline Lateral fusiform & $\mathrm{L}$ & 0.08 & 37 & -42 & -48 & -21 & & & \\
\hline Posterior superior temporal & $\mathrm{R}$ & 0.22 & $21 / 22$ & 54 & -51 & 9 & & & $3.50 *$ \\
\hline Precuneus & B & 0.51 & 7 & 6 & -60 & 45 & $3.16 *$ & & $3.80 *$ \\
\hline Lateral occipital & $\mathrm{L}$ & 0.11 & $18 / 19$ & -30 & -81 & 12 & & & \\
\hline
\end{tabular}

Note L, left; R, right; B, bilateral; BA, Brodmann area.

prolonged nature of these responses is reflected in the event-related plots (bottom row of Fig. 6), as deviations from zero that extend toward the point of speech, which was between 8 and $12 \mathrm{~s}$ after the cue. Regions showing increased responses during memory conditions included bilateral insulae (e.g., region Q), left dorsolateral prefrontal cortex (region S), anterior cingulate sulcus (region K), and left lateral intraparietal sulcus (region T). All of these regions showed evidence of sustained memory-related activity that began with onset of the cue (i.e., also showed positive parameter estimates for cue-related responses to $\mathrm{P}, \mathrm{C}$, and $\mathrm{N}$ conditions relative to the $\mathrm{R}$ condition).

Several regions showed memory-related reductions in delay period activity. The medial anterior orbitofrontal region (region $\mathrm{R}$ ) showed reductions that emerged subsequent to cue onset, in the absence of any memory-related response (in that the parameter estimates for cuerelated responses to P, C, and N conditions did not differ significantly from that for the $\mathrm{R}$ condition). In the case of the cuneus and precuneus regions (not shown), a greater transient response to memory versus repeat cues gave way to a greater delayed response in the repeat conditions. The other regions showing memory-related decreases during the delay period, namely those in right posterior superior temporal cortex (see region $\mathrm{O}$ in Fig. 5) and right lateral inferior occipital cortex, reflected sustained decreases from cue onset.

\section{DISCUSSION}

It is difficult to study recall processes with $\mathrm{fMRI}$, owing to scanner noise and movement artifacts associ-

\section{TABLE 2}

Regions Showing Main Effect of I nterference at Test, for Correct Trials Only, in F Tests at $\mathrm{P}<0.001$ Uncorrected, Together with Talairach Coordinates and Z Scores for Pair-wise Comparisons versus Control Condition That Survive P $<0.05$ Volume Corrected for Main Effect

\begin{tabular}{|c|c|c|c|c|c|c|c|c|}
\hline \multirow[b]{2}{*}{ Region } & \multirow[b]{2}{*}{$\mathrm{L} / \mathrm{R}$} & \multirow[b]{2}{*}{ Size $\left(\mathrm{cm}^{3}\right)$} & \multirow[b]{2}{*}{ BA } & \multicolumn{3}{|c|}{ Coordinates } & \multicolumn{2}{|c|}{ Z } \\
\hline & & & & $x$ & $y$ & $z$ & $\mathrm{~N}>\mathrm{C}$ & $C>P$ \\
\hline \multirow[t]{2}{*}{ Frontopolar } & L & 0.08 & 10 & -27 & 54 & 9 & $3.42^{*}$ & \\
\hline & $\mathrm{R}$ & 0.08 & 10 & 36 & 54 & 9 & $3.48^{*}$ & \\
\hline Lateral orbital frontal & $\mathrm{L}$ & 0.27 & 11 & -39 & 36 & -18 & & $3.69 *$ \\
\hline Ventral inferior frontal & $\mathrm{L}$ & 0.57 & 47 & -42 & 30 & 0 & & $3.53^{*}$ \\
\hline Anterior cingulate sulcus & B & 1.05 & $8 / 32$ & 0 & 15 & 45 & & \\
\hline \multirow[t]{2}{*}{ Caudate head } & $\mathrm{R}$ & 0.35 & - & 18 & 21 & 0 & $3.57 *$ & \\
\hline & $\mathrm{R}$ & 0.08 & - & 15 & 6 & 0 & & \\
\hline Caudate head & $\mathrm{L}$ & 0.46 & - & -9 & 6 & -3 & $3.79^{*}$ & \\
\hline Thalamus & $\mathrm{L}$ & 0.08 & - & -21 & -9 & 21 & $3.48^{*}$ & \\
\hline Cerebellum & B & 0.32 & - & 9 & -51 & -12 & $4.08 *$ & \\
\hline Intraparietal sulcus & $\mathrm{R}$ & 0.08 & 7 & 36 & -66 & 42 & $3.41^{*}$ & \\
\hline Precuneus/superior parietal & $\mathrm{L}$ & 0.16 & 7 & -3 & -69 & 54 & $3.50^{*}$ & \\
\hline
\end{tabular}

Note L, left; R, right; B, bilateral; BA, Brodmann area. 
TABLE 3

Regions Showing Main Effect of Interference at Test, for All Trials, in F Tests at $\mathrm{P}<0.001$ Uncorrected, Together with Talairach Coordinates and Z Scores for Pair-wise Comparisons versus Control Condition That Survive P $<0.05$ Volume Corrected for Main Effect

\begin{tabular}{|c|c|c|c|c|c|c|c|c|}
\hline \multirow[b]{2}{*}{ Region } & \multirow[b]{2}{*}{$L / R$} & \multirow[b]{2}{*}{ Size $\left(\mathrm{cm}^{3}\right)$} & \multirow[b]{2}{*}{$\mathrm{BA}$} & \multicolumn{3}{|c|}{ Coordinates } & \multicolumn{2}{|c|}{ z } \\
\hline & & & & $x$ & $y$ & z & $\mathrm{N}>\mathrm{C}$ & $C>P$ \\
\hline Inferior frontal sulcus & $\mathrm{R}$ & 0.30 & 46 & 30 & 45 & 27 & $3.37 *$ & \\
\hline Lateral orbital frontal & $\mathrm{L}$ & 0.22 & 11 & -42 & 39 & -18 & & $3.41 *$ \\
\hline Ventral inferior frontal & $\mathrm{L}$ & 0.49 & 47 & -42 & 30 & 0 & & \\
\hline Ventral inferior frontal sulcus & L & 0.11 & 45 & -27 & 30 & 6 & & \\
\hline Anterior insula & $\mathrm{R}$ & 0.11 & - & 30 & 24 & -15 & & $3.86 *$ \\
\hline Anterior cingulate sulcus & B & 1.59 & $8 / 32$ & -3 & 24 & 39 & & $3.84 *$ \\
\hline \multirow[t]{2}{*}{ Caudate head } & $\mathrm{R}$ & 0.08 & - & 15 & 21 & 3 & & \\
\hline & $\mathrm{L}$ & 0.11 & - & -21 & 12 & 0 & & \\
\hline \multirow[t]{2}{*}{ Caudate } & $\mathrm{R}$ & 0.38 & - & 15 & 6 & 0 & & \\
\hline & $\mathrm{L}$ & 0.11 & - & -15 & 6 & 3 & & \\
\hline Superior frontal gyrus & $\mathrm{L}$ & 0.16 & 6 & -30 & 6 & 57 & & \\
\hline Subthalamic & $\mathrm{R}$ & 0.19 & - & 18 & -18 & -12 & $3.46^{*}$ & \\
\hline Cuneus & $\mathrm{L}$ & 0.49 & 19 & -6 & -54 & 0 & & \\
\hline Cerebellum & $\mathrm{B}$ & 0.13 & - & 3 & -48 & -18 & $3.67 *$ & \\
\hline
\end{tabular}

Note L, left; R, right; B, bilateral; BA, Brodmann area.

ated with overt speech. The present study used a novel method that overcomes these problems. In particular, we examined processes involved when participants en- counter proactive interference during a cued-recall paradigm. The paradigm was successful in producing poorer recall and more intralist intrusions under con-

\section{TABLE 4}

Regions of at Least 10 Voxels Showing a Cue-Related Memory Effect (Conditions $\mathrm{P}, \mathrm{C}$, and $\mathrm{N}$ versus $\mathrm{R}$ ) in t Tests at $\mathrm{P}<0.001$, Two-Tailed, Uncorrected

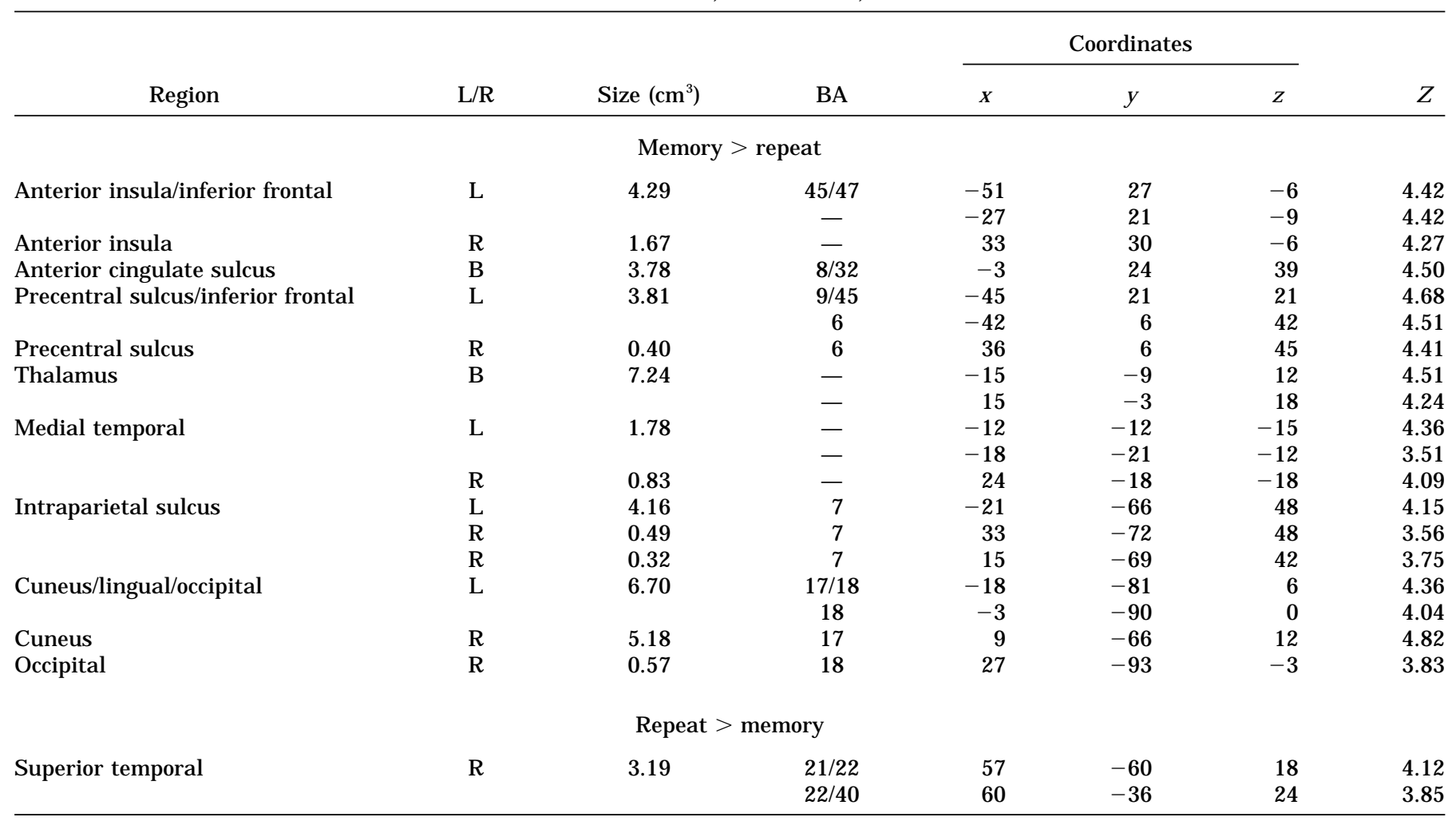




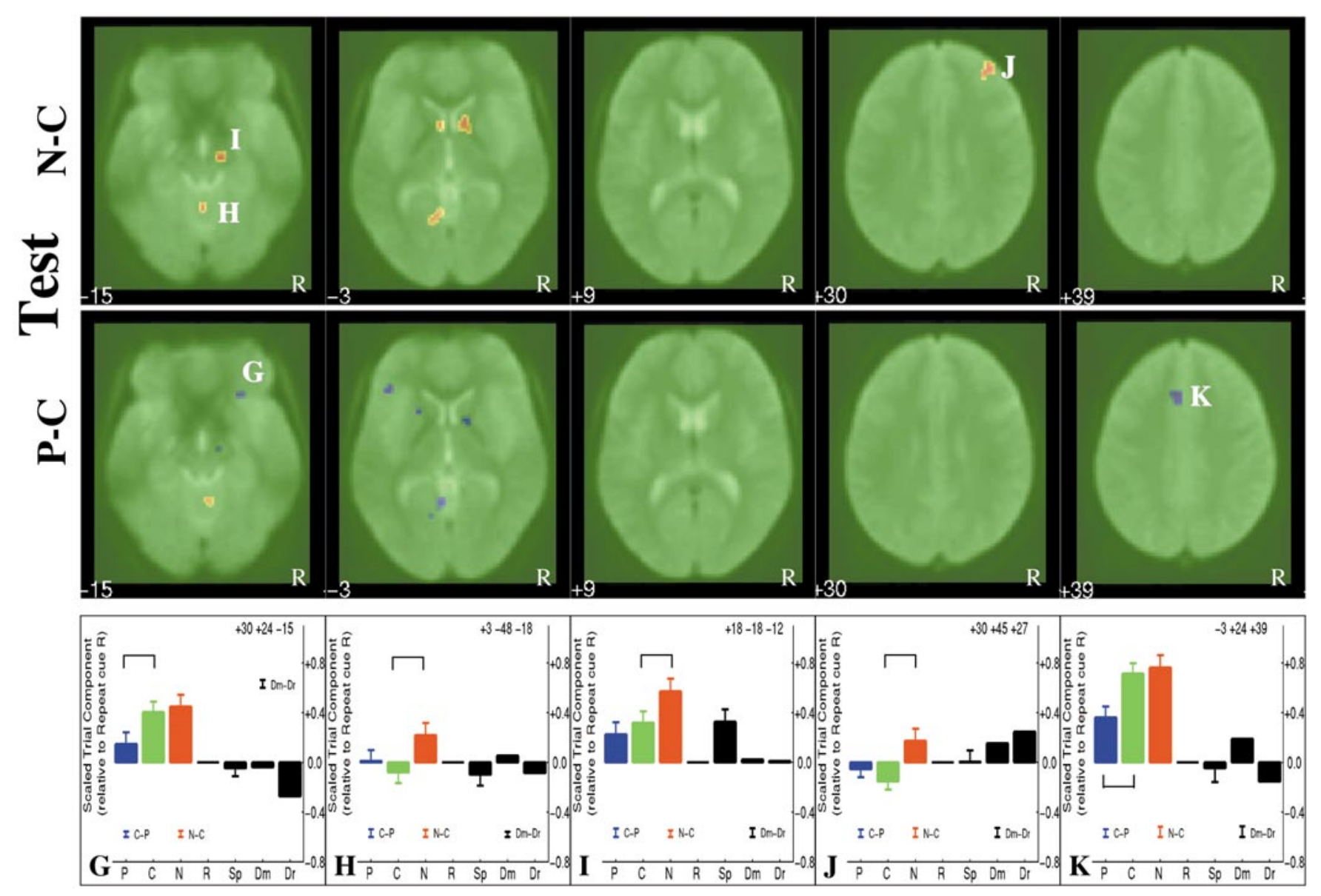

FIG. 4. Interference effects at Test, all trials (correct and incorrect). See legend to Fig. 3 for more details.

ditions of high proactive interference. Consistent with neuropsychological studies of patients with frontal lesions, several frontal regions, most notably in bilateral frontopolar, left inferior, and right dorsolateral prefrontal cortices, showed responses that were influenced by the level of proactive interference. Furthermore, comparisons against a nonmemory control condition revealed a network of other regions implicated in cued recall, including bilateral medial temporal, thalamic, premotor, and intraparietal regions, as well as regions implicated in maintaining a verbal response during the delay between visual cue and spoken output, including bilateral insulae, left dorsolateral prefrontal cortex, anterior cingulate, and left lateral parietal cortex. We begin by discussing the detailed pattern of prefrontal responses at Study and at Test, in relation to previous imaging studies, before considering the responses of more posterior brain regions.

\section{Interference Effects in the Study Phase}

The left inferior frontal regions showing interference effects during the Study phase were highly consistent with previous studies. The response of these regions decreased when a cue was repeated with the same associate ( $P$ condition), but increased when the cue was paired with a novel associate ( $\mathrm{N}$ condition). The more posterior region, which extended into inferior frontal sulcus and probably included aspects of dorsolateral prefrontal cortex, has shown similar interference effects in previous studies of encoding. Dolan and Fletcher (1997), for example, found a greater response in this region when one word in a pair was repeated and one was novel (analogous to the present $\mathrm{N}$ condition), relative to when both were repeated (analogous to the present $\mathrm{P}$ condition) or both were novel (analogous to the present C condition). F letcher et al. (2000) found that the same region showed a greater response when pairs of repeated words were rearranged than when they were initially presented.

The more anterior left inferior frontal gyrus regions, in ventrolateral prefrontal cortex, have previously been implicated in semantic processing (Gabrieli et al., 1996; Poldrack et al., 1998), and decreases in their response have been associated with semantic priming (e.g., Demb et al., 1995; Wagner et al., 2000). Given that the present Study task was to detect the semantic 

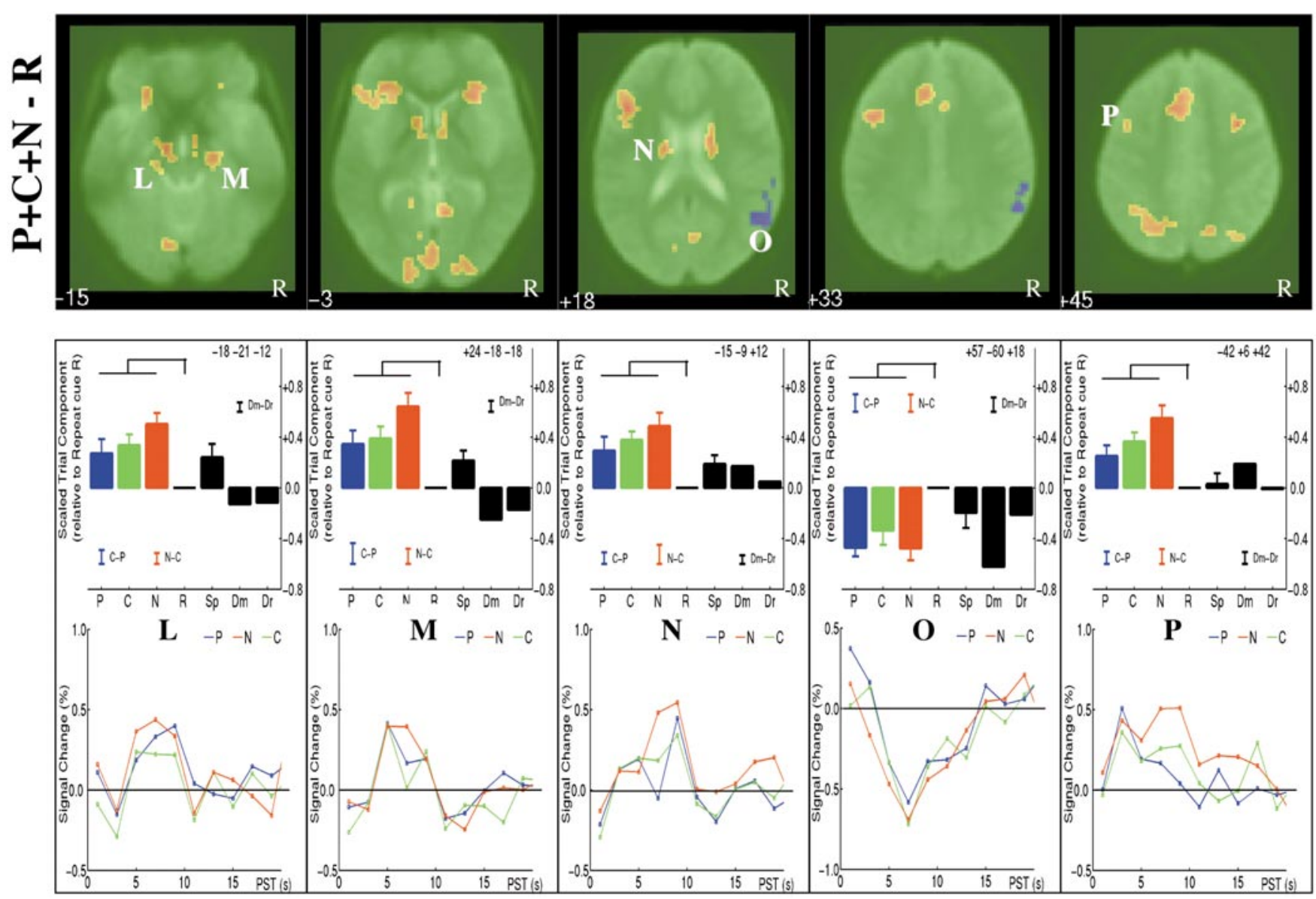

FIG. 5. Cue-related memory effects at Test. Colored regions show differences in average cuerelated response to memory (P, C, and $N$ ) versus nonmemory $(R)$ conditions $(P<0.001$, two-tailed, uncorrected). Middle row shows estimates of trial components, relative to the cue-related component in $\mathrm{R}$ trials, from the maxima of regions $\mathrm{L}-\mathrm{P}$. See legend to Fig. 3 for more details. The bottom row shows averaged cue-locked BOLD responses for $\mathrm{P}, \mathrm{C}$, and $\mathrm{N}$ trials, in terms of percentage signal change relative to R trials, binned every $2 \mathrm{~s}$ of poststimulus time (PST) using a finite impulse response model having adjusted for speech events, error trials, and movement confounds.

relationship between cue and associate, a similar priming effect could explain the decreased response to repeated cue-associate pairings (i.e., across P1-P3). However, this account would appear unable to explain the increased response when a previous pairing was changed (N2 or N3), relative to a novel pairing (N1 or C).

Rather, a better account of the present findings, for both anterior and posterior left inferior frontal regions, would appear to be the "selection" ideas of ThompsonSchill, D'Esposito, and Kan (1999) and Fletcher et al. (2000). These authors proposed that left inferior frontal cortex is responsible for selecting among competing responses, which entails both activating appropriate response attributes and inhibiting inappropriate attributes or schemas. The response decrease observed when a word pair is repeated in a semantic-processing task (as in the present $\mathrm{P} 3$ versus $\mathrm{C}$ comparison) would then be attributed to reduced selection demands when the same semantic attributes had been activated recently. The response increase when a word pairing is changed (as in the present N3 versus C comparison) would then be attributed to the increased selection demands necessary to inhibit previous semantic attributed that are no longer relevant to the new association. This could involve deliberate forgetting of the original N 1 pairs (e.g., Bjork, 1989; Anderson and Neely, 1996).

A second pair of prefrontal regions, in left and right frontopolar cortex, showed a different pattern, with increased responses in both P3 and N3 conditions relative to the $\mathrm{C}$ condition. In other words, these regions showed increased responses whenever a cue was repeated, regardless of whether the paired associate was repeated or novel. This pattern is unlikely to reflect an attentional bias toward the final items in a Study session because $C$ trials were intermixed with N3 and P3 trials and because responses to $C$ trials did not differ reliably from those to $\mathrm{P} 1$ and $\mathrm{N} 1$ trials. Moreover, the increase relative to $C$ trials appeared as great for second (N2 and P2) as for third (N3 and P3) presentations. Given that frontopolar cortex has previously been implicated in successful episodic retrieval (see, for exam- 


\section{TABLE 5}

Regions of at Least 10 Voxels Showing a Memory Effect during the Delay Interval (Dm versus Dr Trial Components) in t Tests at $\mathrm{P}<0.001$, Two-Tailed, Uncorrected

\begin{tabular}{|c|c|c|c|c|c|c|c|}
\hline \multirow[b]{2}{*}{ Region } & \multirow[b]{2}{*}{$L / R$} & \multirow[b]{2}{*}{ Size $\left(\mathrm{cm}^{3}\right)$} & \multirow[b]{2}{*}{ BA } & \multicolumn{3}{|c|}{ Coordinates } & \multirow[b]{2}{*}{ Z } \\
\hline & & & & $x$ & y & $z$ & \\
\hline \multicolumn{8}{|c|}{ Memory $>$ repeat } \\
\hline Inferior frontal sulcus & L & 0.73 & 9/46 & -42 & 27 & 27 & 3.94 \\
\hline \multirow{2}{*}{ Anterior insula } & $\bar{L}$ & 0.92 & - & -39 & 18 & -15 & 3.92 \\
\hline & $\mathrm{R}$ & 1.97 & - & 33 & 21 & -9 & 4.28 \\
\hline Anterior cingulate sulcus & B & 1.54 & $8 / 32$ & 0 & 33 & 36 & 3.67 \\
\hline Lateral intraparietal & L & 0.30 & $7 / 40$ & -39 & -54 & 54 & 3.70 \\
\hline \multicolumn{8}{|c|}{ Repeat $>$ memory } \\
\hline Anterior medial frontal & B & 1.40 & 10 & $\begin{array}{r}-9 \\
6\end{array}$ & $\begin{array}{l}48 \\
60\end{array}$ & $\begin{array}{r}-12 \\
3\end{array}$ & $\begin{array}{l}3.95 \\
3.36\end{array}$ \\
\hline Cuneus & B & 0.95 & 31 & 0 & -57 & 18 & 3.61 \\
\hline Precuneus & B & 0.86 & 7 & -3 & -57 & 45 & 3.75 \\
\hline Inferior lateral occipital & $\mathrm{R}$ & 0.32 & 19 & 54 & -69 & -9 & 4.04 \\
\hline Middle occipital/temporal & $\mathrm{R}$ & 1.81 & 19/37 & 36 & -84 & 21 & 3.66 \\
\hline & & & $21 / 22$ & 60 & -57 & 15 & 3.55 \\
\hline
\end{tabular}

ple, Rugg and Henson, 2002), one possible explanation is that the pattern reflects covert retrieval, during the Study phase, of a previous episode in which that cue was presented (e.g., P1 or N1). However, the pattern of responses at Test (see below) suggest a more complex function for frontopolar cortex.

\section{Interference Effects in the Test Phase}

Event-related analyses are generally restricted to trials with correct task performance, for which one expects the relevant processes to be operating appropriately. However, there was a high rate of errors (28\%) in the $\mathrm{N}$ condition, of which the majority were intralist intrusions. The processes involved in confronting proactive interference are likely to be especially stressed on such trials. There were too few errors in the other two conditions to allow a factorial investigation of the correct/incorrect trials across the three retrieval conditions. Nonetheless, following a reviewer's suggestion, we performed an additional analysis on all trials, including the potentially more sensitive error trials. We treat effects obtained with both analyses as clear-cut and those obtained in only one analysis as provisional, in need of further confirmation.

\section{Interference Effects Found in Both Analyses}

Proactive interference effects at Test were seen in regions similar to those at Study, particularly in two regions of left inferior frontal cortex. However, these left inferior frontal regions showed different patterns of responses across the $\mathrm{P}, \mathrm{C}$, and $\mathrm{N}$ conditions, namely, a reduced response in the $P$ relative to $C$ condition, as found during Study, but little difference between $C$ and $\mathrm{N}$ conditions, unlike during Study.

One explanation for this left inferior frontal interference pattern is that participants adopted a "generateand-recognize" approach to cued recall (Watkins and Gardiner, 1979). According to this hypothesis, participants repeatedly generated semantic associates of the cue until one was recognized from the Study phase (a strategy encouraged by the strong semantic relationship between cue and target and consistent with the semanticrelatedness of the extralist intrusions). If so, the greater response to $\mathrm{C}$ and $\mathrm{N}$ conditions than $\mathrm{P}$ condition would reflect greater generation demands (or attribute activation in the "selection" account above). This is because, after three Study pairings, the cue-target association in the P condition is likely to become "schematized" (Burgess and Shallice, 1996), such that the target is an automatic response to the appearance of the cue. Furthermore, the $\mathrm{C}$ condition would involve greater generation demands at Test than at Study, when the associate is provided. This might explain the smaller difference be tween $\mathrm{C}$ and $\mathrm{N}$ conditions at Test compared to Study, with the increased activation demands overcoming any differences in inhibitory selection demands. To assess the importance of generation/activation as a factor, the cue target association frequency could be manipulated. To assess the importance of inhibitory selection, the semantic relatedness between the set of studied associates could be manipulated.

\section{Interference Effects That Varied with Performance}

The activation differences across conditions for the bilateral frontopolar regions reached significance only 
when analysis was restricted to correct responses. However, their bilateral nature, together with their similarity to the sites found at Study, supports a genuine sensitivity to proactive interference. These re gions showed a greater response in the $\mathrm{N}$ condition than in the $C$ condition, as found during Study, but little difference between $C$ and $P$ conditions, unlike during Study. This pattern is difficult to explain in terms of the all-or-none episodic retrieval we proposed for the frontopolar responses at Study.

The greatest response to the $\mathrm{N}$ condition at Test is consistent with other accounts of memory-related frontopolar activity, such as the amount of "retrieval effort" (Buckner et al., 1998) or the number of responses generated from a cue (Allan et al., 2000). However, both accounts have difficulty explaining the similar re sponse to $C$ and $P$ conditions at Test. The accuracy data, as well as subjective reports, strongly suggest that responses to $P$ cues were less effortful than to $C$ cues, and according to the generate-and-recognize the ory above, a greater number of semantic associates are likely to be generated to $C$ than to $P$ cues.

One possibility is that the frontopolar response increased parametrically with the amount of information retrieved from episodic memory. This would occur, for example, if participants attempted to retrieve all three associates of the $\mathrm{N}$ cue, before selecting the most re cent. This would entail maintaining one or two associates in mind while attempting to retrieve (e.g., generate and recognize) the remaining associates. This situation of maintaining the products of one task online while switching to another resembles the "branching" function attributed to frontopolar cortex by Koechlin et al. (1999); see also Burgess et al. (2000) and Fletcher and Henson (2001). The episodic retrieval of a previous associate to $\mathrm{P}$ and $\mathrm{N}$ cues during Study, while performing a concurrent semantic task, may also have produced frontopolar responses, though it would be less important to retrieve all previous associates, possibly explaining the lack of a parametric effect of N3 versus N2 at Study.

Right dorsolateral prefrontal cortex showed interference effects only when all trials, including errors, were analyzed. This finding supported a prediction deriving from our previous monitoring account of prefrontal activations during episodic retrieval (Shallice et al., 1994). Monitoring refers to the process of checking the validity, or sufficiency, of the information retrieved from episodic memory in response to a cue, and an impairment of monitoring has been used to explain some types of confabulation following frontal lesions (Burgess and Shallice, 1996). Our previous operationalizations of monitoring, which include free versus cued recall (Fletcher et al., 1998), exclusion by source (Henson et al., 1999a), familiarity in the absence of recollection (Henson et al., 1999b), and low confidence recognition judgments (Henson et al., 2000), have all produced dorsolateral prefrontal activations (sometimes in addition to other prefrontal regions), either on the right or bilaterally. One would therefore expect increased monitoring demands during cued recall under conditions of high interference to lead to increased activation in dorsolateral prefrontal cortex, as was found. Indeed, greater monitoring might be expected for "difficult" trials, in which encoding of episodic information (such as temporal order) was poor, for example, and for which recall fails.

\section{0 ther Prefrontal Regions}

Another prefrontal region that might have been predicted to show interference effects is orbitofrontal cortex, lesions in which have been associated with an inability to suppress previously relevant information (Schnider and Ptak, 1999). I ndeed, medial orbitofrontal activations associated with such suppression were obtained in a PET study of healthy volunteers (Schnider et al., 2000). It is possible that more medial orbitofrontal activations did occur in the present study, but were not detected owing to the susceptibility artifacts that arise near these regions with EPI (evident as the reduced image intensity around medial orbital re gions in the $z=-18$ slice, e.g., in Fig. 3).

\section{Posterior Regions Associated with Cued Recall}

Several more posterior regions showed interference effects at Study and/or Test. The precuneus, which has also been associated with successful episodic retrieval (Fletcher et al., 1995; Rugg and Henson, 2002), showed a response pattern similar to that in the frontopolar regions at both Study and Test. Bilateral regions in the head of caudate also showed an interference pattern at Test like the frontopolar regions. Regions in midcerebellum, thalamus, and anterior cingulate showed a more graded pattern of responses at Test that appeared to increase monotonically across $\mathrm{P}, \mathrm{C}$, and $\mathrm{N}$ conditions. Finally, a right superior temporal region showed response decreases for $\mathrm{C}$ relative to $\mathrm{P}$ conditions at Study and for $\mathrm{P}, \mathrm{C}$, and $\mathrm{N}$ conditions relative to the $\mathrm{R}$ condition at Test. Superior temporal response decreases were also seen in our previous study (Henson et al., 1998) and may reflect the searching of semantic associative networks (Friston et al., 1991).

Several medial temporal and diencephalic regions showed a main effect of cued recall, i.e., greater cuerelated responses in the $\mathrm{P}, \mathrm{C}$, and $\mathrm{N}$ conditions than in the $\mathrm{R}$ condition. These included bilateral regions within the vicinity of the hippocampal formation and bilateral thalamus. Their activation during episodic retrieval is consistent with the well-known amnesia resulting from damage to these regions (Mayes, 1988). Medial temporal retrieval-related activations have not typically been found in event-related fMRI studies of verbal recognition memory (Rugg and Henson, 2002). 

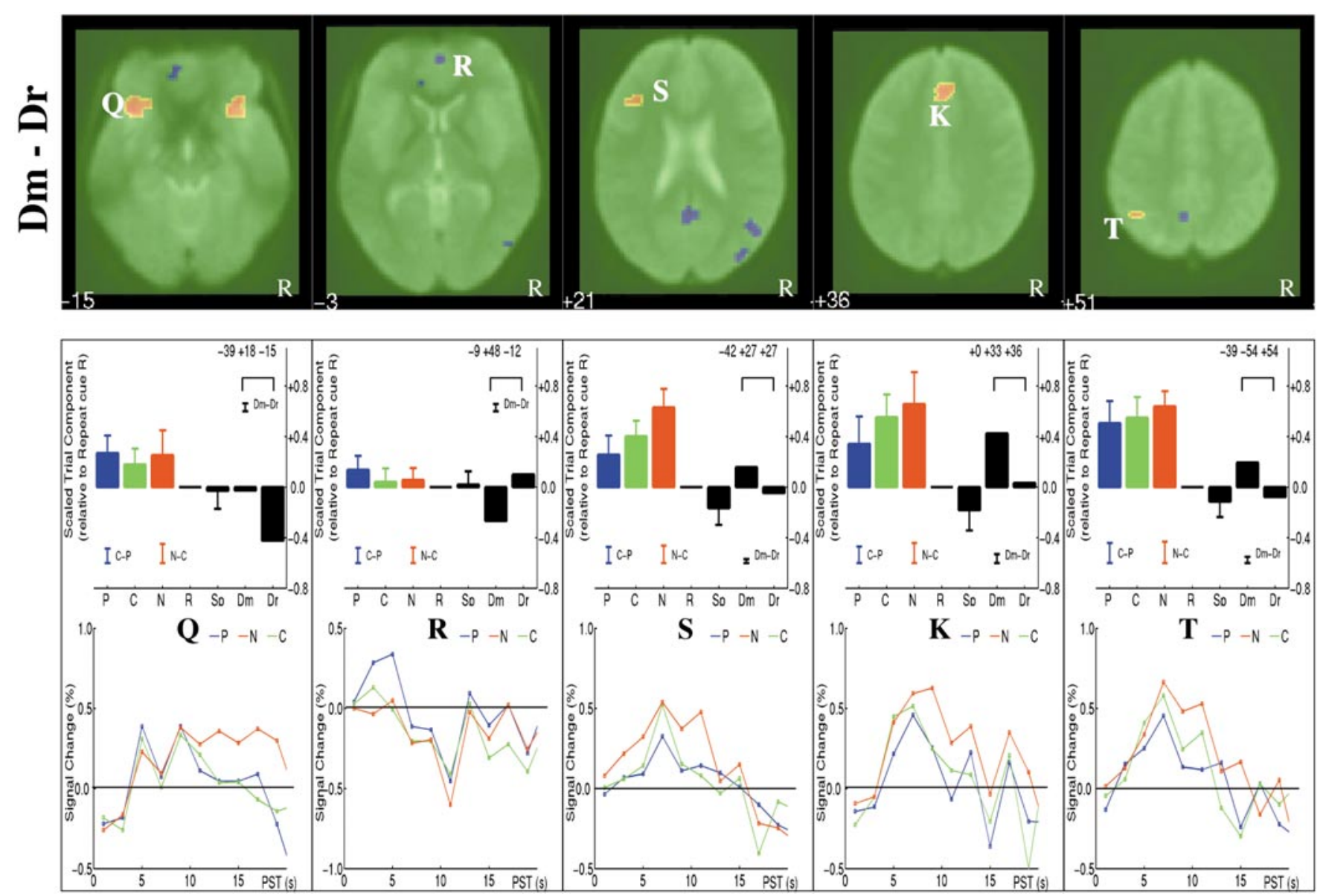

FIG. 6. Delay-related memory effects at Test. Colored regions show differences in delay-related response to memory (Dm) versus nonmemory (Dr) conditions ( $<<0.001$, two-tailed, uncorrected). See legend to Fig. 5 for more details.

This may reflect the fact that recall is a purer measure of episodic retrieval than recognition, since the latter may include a nonepisodic familiarity component (Mandler, 1980).

A few regions showed memory-related effects that persisted into the delay period. These included bilateral insulae, left dorsolateral prefrontal, anterior cingulate, and left lateral parietal regions, which showed increased responses relative to the $\mathrm{R}$ condition, and anterior medial frontal and occipital regions, which showed relative decreases. These effects might reflect the maintenance of a verbal response over the 8-12 s between the cue and the speech prompt.

\section{Further Considerations}

What are the precise processes involved in attempting to reduce the effects of proactive interference? While the prefrontal regions identified in the present study might be responsiblefor the inhibition or suppression of various sources of interference during recall (Schnider and Ptak, 1999; Shimamura, 1994), a more precise functional characterization would require detailed models of the retrieval process. For example, the prefrontal regions might be responsible for specifying a temporal window spanning the end of the Study phase, which is used as a cue to retrieve only the more recent pairing episodes from memory (e.g., Glenberg et al., 1983). Alternatively, all the associates of a cue might be retrieved from episodic memory, after which the prefrontal regions would be responsible for comparing their contextual associations, or relative "strengths," along a dimension that correlates with recency. The present design cannot distinguish the amount of information recalled from the comparison or monitoring of that information. One step in this direction would be to compare $\mathrm{N}$ cues under different task instructions: One task would be to report any associate, while in another it would be to report the most recent one, which should stress monitoring processes (assuming that all associates are automatically re trieved in response to the cue).

\section{CONCLUSION}

This study is one of the first to attempt overt spoken recall during event-related $\mathrm{fMRI}$. The use of recall tasks opens the door to a new range of $\mathrm{fMRI}$ experi- 
ments on memory retrieval that overcome the limitations of recognition tests. Indeed, the subtly different pattern of results observed in the Study and Test phases (e.g., in left inferior frontal cortex) might indicate important differences between paired-associate recognition and paired-associate recall. The present paradigm clearly showed effects of proactive interference in prefrontal cortex, consistent with the increased susceptibility to interference in patients with frontal lesions. Moreover, at least two, if not three, different regions within frontal cortex-in left inferior, bilateral frontopolar, and right dorsolateral prefrontal cortices-showed different patterns of activity across our $\mathrm{P}$, $\mathrm{C}$, and $\mathrm{N}$ conditions. This supports the proposal of functional specialization of memory-related functions within prefrontal cortex (Christoff and Gabrieli, 2000; Fletcher and Henson, 2001). It is hoped that such dissociations will prompt more detailed models of the memory control processes involved in coping with proactive interference.

\section{ACKNO WLEDGMENTS}

This work is funded by Wellcome Trust Fellowship 060924. R.H. and R.J .D. are supported by the Well come Trust. The authors thank Daniel Glaser for analytical assistance. The authors also thank one referee for suggesting an additional analysis.

\section{REFERENCES}

Allan, K., Dolan, R. J ., Fletcher, P. C., and Rugg, M. D. 2000. The role of the right anterior prefrontal cortex in episodic retrieval. NeuroI mage 11: 217-227.

Anderson, M. C., and Neely, J. H. 1996. Interference and inhibition in memory retrieval. In Handbook of Perception and Cognition (E. L. Bjork and R. A. Bjork, Eds.), pp. 237-313. Academic Press, San Diego.

Ashburner, J ., and Friston, K. J . 1999. Nonlinear spatial normalization using basis functions. Hum. Brain Mapping 7: 254-266.

Barch, D. M., Sabb, F. W., Carter, C. S., Braver, T. S., Noll, D. C., and Cohen, J . D. 1999. Overt verbal responding during fMRI scanning: Empirical investigations of problems and potential solutions. Neurol mage 10: 642- 657.

Birn, R. M., Bandettini, P. A., Cox, R. W., and Shaker, R. 1998. fMRI during stimulus correlated motion and overt subject responses using a single trial paradigm. In Proceedings of ISMRM Sixth Scientific Meeting, Sydney, p. 159.

Bjork, R. A. 1989. Retrieval inhibition as an adaptive mechanism in human memory. In Varieties of Memory and Consciousness: Essays in Honour of Endel Tulving (H. L. Roediger, III and F. I. M. Craik, Eds.), pp. 309-330. Erlbaum, Hillsdale, NJ .

Brodmann, K. 1909. Vergl eichende Lokal isationsl ehreder Grosshirnrinde in Ihren Prinzipien Dargelstelt auf Grund des Zellesbaues. Barth, Leipzig.

Buckner, R. L., Koutstaal, W., Schacter, D. L., Wagner, A. D., and Rosen, B. R. 1998. Functional-anatomic study of episodic retrieval. I. Retrieval effort versus retrieval success. Neurol mage 7: 151-162.

Burgess, P. W., and Shallice, T. 1996. Confabulation and the control of recollection. Memory 4: 359-411.
Burgess, P. W., Veitch, E., de Lacy Costello, A. and Shallice, T. 2000. The cognitive and neuroanatomical correlates of multitasking. Neuropsychologia 38: 848-863.

Christoff, K., and Gabrieli, J . D. E. 2000. The frontopolar cortex and human cognition: Evidence for a rostrocaudal hierarchical organization within the human prefrontal cortex. Psychobiology 28: 168186.

Cocosco, C. A., Kollokian, V., Kwan, R. K. S., and Evans, A. C. 1997. Brainweb: Online interface to a 3D MRI simulated brain database. Neurol mage 5: 425.

Demb, J . B., Desmond, J . E., Wagner, A. D., Vaidya, C. J ., Glover, G. H., and Gabrieli, J. D. 1995. Semantic encoding and retrieval in the left inferior prefrontal cortex: A functional MRI study of task difficulty and process specificity. J . Neurosci. 15: 5870-5878.

Dolan, R. J ., and Fletcher, P. C. 1997. Dissociating prefrontal and hippocampal function in episodic memory encoding. Nature 388: 582-585.

Fletcher, P., Frith, C. D., Baker, S., Shallice, T., Frackowiak, R. S. J ., and Dolan, R. J . 1995. The mind's eye-Activation of the precuneus in memory related imagery. Neurol mage 2: 196-200.

Fletcher, P. C., and Henson, R. N. 2001. Frontal lobes and human memory: Insights from functional neuroimaging. Brain 124: 849881.

Fletcher, P. C., Shallice, T., and Dolan, R. J . 2000. Sculpting the response space: An account of left prefrontal activation at encoding. Neurol mage 12: 404- 417.

Fletcher, P. C., Shallice, T., Frith, C. D., Frackowiak, R. S. J ., and Dolan, R. J . 1998. The functional roles of the prefrontal cortex in episodic memory. II. Retrieval. Brain 121: 1249-1256.

Friston, K. J ., Ashburner, J ., Frith, C. D., Poline, J .-B., Heather, J. D., and Frackowiak, R. S. J. 1995a. Spatial registration and normalisation of images. Hum. Brain Mapping 2: 165-189.

Friston, K. J ., Fletcher, P., J osephs, O., Holmes, A., Rugg, M. D., and Turner, R. 1998. Event-related fMRI: Characterizing differential responses. Neurol mage 7: 30-40.

Friston, K. J ., Frith, C. D., Liddle, P., and Frackowiak, R. S. J . 1991. Investigating a network model of word generation with positron emission tomography. Proc. R. Soc. London B 244: 101-106.

Friston, K. J ., Holmes, A. P., Worsley, K.J ., Poline, J . B., Frith, C. D., and Frackowiak, R. S. J . 1995b. Statistical parametric maps in functional imaging: A general linear approach. Hum. Brain Mapping 2: 189-210.

Gabrieli, J . D. E., Desmond, J . E., Demb, J . B., Wagner, A. D., Stone, M. V., Vaidya, C. J ., and Glover, G. H. 1996. Functional magnetic resonance imaging of semantic memory processes in the frontal lobes. Psychol. Sci. 7: 278-283.

Glaser, D. E., Penny, W. D., Henson, R. N. A., Rugg, M. D., and Friston, K. J . 2001. Correcting for non-sphericity in imaging data using classical and Bayesian approaches. Neurol mage 13: 127.

Glenberg, A. M., Bradley, M. M., Kraus, T. A., and Renzaglia, G. J . 1983. Studies of the long-term recency effect: Support for a contextually guided retrieval hypothesis. J. Exp. Psychol. Learning Memory Cognit. 9: 231-255.

Henson, R. N. A., Shallice, T., and Dolan, R. J. 1998. Proactive interference in episodic memory retrieval. Neurol mage 7: 879.

Henson, R. N., Shallice, T., and Dolan, R. J . 1999a. Right prefrontal cortex and episodic memory retrieval: A functional MRI test of the monitoring hypothesis. Brain 122: 1367-1381.

Henson, R. N. A., Rugg, M. D., Shallice, T., J osephs, O., and Dolan, R. 1999b. Recollection and familiarity in recognition memory: An event-related fMRI study. J . Neurosci. 19: 3962-3972.

Henson, R. N. A., Rugg, M. D., Shallice, T., and Dolan, R. J . 2000. Confidence in recognition memory for words: Dissociating right prefrontal roles in episodic retrieval. J . Cognit. Neurosci. 12: 913-923. 
Holmes, A. P., and Friston, K. J. 1998. Generalizability, random effects and population inference. Neurol mage 7: 754.

Incisa Della Rocchetta, A., and Milner, B. 1993. Strategic search and retrieval inhibition: The role of the frontal lobes. Neuropsychol ogia 31: 503-524.

J anowsky, J. S., Shimamura, A. P., and Squire, L. R. 1989. Source memory impairment in patients with frontal lobe lesions. Neuropsychologia 27: 1043-1056.

Kiss, G. R., Armstrong, C., Milroy, R., and Piper, J . 1973. An associative thesaurus of English and its computer analysis. In The Computer and Literary Studies (A. J . Aitken, R. W. Bailey, and N. Hamilton-Smith, Eds.). Edinburgh Univ. Press, Edinburgh.

Koechlin, E., Basso, G., Pietrini, P., Panzer, S., and Grafman, J. 1999. The role of the anterior prefrontal cortex in human cognition. Nature 399: 148-151.

Mandler, G. 1980. Recognizing: The judgement of previous occurrence. Psychol. Rev. 87: 252-271.

Mayes, A. R. 1988. Human Organic Memory Disorders. Cambridge Univ. Press, Cambridge, UK.

Milner, B., Corsi, P., and Leonard, G. 1991. Frontal-Iobe contribution to recency judgements. Neuropsychologia 29: 601- 618.

Moscovitch, M., and Melo, B. 1997. Strategic retrieval and the frontal Iobes: Evidence from confabulation and amnesia. Neuropsychologia 35: 1017-1034.

Palmer, E. D., Rosen, H. J ., Ojemann, J . G., Buckner, R. L., Kelley, W. M., and Petersen, S. E. 2001. An event-related fMRI study of overt and covert word stem completion. Neurol mage 14: 182-193.

Poldrack, R. A., Wagner, A. D., Prull, M. W., Desmond, J . E., Glover, G. H., and Gabrieli, J. D. E. 1998. Functional specialization for semantic and phonological processing in left inferior prefrontal cortex. Neurol mage 10: 15-35.

Rugg, M. D., and Henson, R. N. A. 2002. E pisodic memory retrieval: An (event-related) functional neuroimaging perspective. In The Cognitive Neuroscience of Memory Encoding and Retrieval (A. E. Parker, E. L. Wilding, and T. Bussey, Eds.). Psychology Press, London, UK, in press.

Schnider, A., and Ptak, R. 1999. Spontaneous confabulators fail to suppress currently irrelevant memory traces. Nat. Neurosci. 2: 677-681.
Schnider, A., Treyer, V., and Buck, A. 2000. Selection of currently relevant memories by the human posterior medial orbitofrontal cortex. J . Neurosci. 20: 5880-5884.

Shallice, T., Fletcher, P., Frith, C. D., Grasby, P., Frackowiak, R. S. J ., and Dolan, R. J . 1994. Brain regions associated with acquisition and retrieval of verbal episodic memory. Nature 368: 633- 635.

Shimamura, A. P. 1994. Memory and frontal lobe function. In The Cognitive Neurosciences (M. S. Gazzaniga, Ed.), pp. 803- 814. MIT Press, Cambridge, MA.

Shimamura, A. P., J anowsky, J . S., and Squire, L. R. 1990. Memory for the temporal order of events in patients with frontal lobe lesions and amnesic patients. Neuropsychologia 28: 803-814.

Shimamura, A. P., J urica, P. J ., Mangels, J . A., Gershberg, F. B., and Knight, R. T. 1995. Susceptibility to memory interference effects following frontal lobe damage: Findings from paired-associate learning. J . Cognit. Neurosci. 7: 144-152.

Strange, B. A., Fletcher, P. C., Henson, R. N., Friston, K. J ., and Dolan, R. J . 1999. Segregating the functions of human hippocampus. Proc. Natl. Acad. Sci. USA 96: 4034- 4039.

Stuss, D. T., Alexander, M. P., Palumbo, C. L., Buckle, L., Sayer, L., and Pogue, J. 1994. Organisational strategies of patients with unilateral or bilateral frontal lobe injury in word list learning tasks. Neuropsychology 8: 355-373.

Talairach, J ., and Tournoux, P. 1988. Co-planar Stereotaxic Atlas of the Human Brain. Thieme, Stuttgart.

Thompson-Schill, S. L., D'Esposito, M., and Kan, I. P. 1999. Effects of repetition and competition on activity in left prefrontal cortex during word generation. Neuron 23: 513-522.

Wagner, A. D., Koutstaal, W., Maril, A., Schacter, D. L., and Buckner, R. L. 2000. Task-specific repetition priming in left inferior prefrontal cortex. Cereb. Cortex 10: 1176-1184.

Watkins, M. J ., and Gardiner, J . M. 1979. An appreciation of generate-recognize theory of recall. J . Verbal Learning Verbal Behav. 18: $687-704$.

Worsley, K. J ., Marrett, S., Neelin, P., Vandal, A. C., Friston, K. J ., and Evans, A. C. 1995. A unified approach for determining significant signals in images of cerebral activation. Hum. Brain Mapping 4: 58-73. 